The Research Journal of the Costume Culture

[Original Article]

Received June 28, 2017

Revised August 23, 2017

Accepted August 28, 2017

${ }^{\dagger}$ Corresponding author

(jewels21@hanmail.net)

ORCID

JIYOUN HONG

http://orcid.org/0000-0003-1700-0675

\section{The color characteristics of Cartier's exotic design in the early 20th century}

\author{
Jiyoun Hong ${ }^{\dagger}$ \\ Dept. of Jewelry \& Metals, Dongyang University, Korea \\ 20세기 초 까르띠에의 이국적 디자인의 색상 특성 \\ 홍 지 연 $^{\dagger}$ \\ 동양대학교 보석귀금속학과
}

\begin{abstract}
As the international competitive landscape deepens, the need to understand foreign cultures and establish effective strategies is increasing. At the beginning of the 20th century, Cartier actively developed exotic designs to secure international competitiveness; theses designs have also been used as design prototypes for Cartier in modern times. The purpose of this study is to analyze the color characteristics and types of exotic designs in the early 20th century, which was a turning point in Cartier's design. After studying the literature, a total of 248 exotic designs were presented in Cartier catalogs. This study also selected overseas monographs from the early 20th century, and their design types were classified and color analysis was performed based on the Natural Color System(NCS). Cartier's exotic designs cover wide range of styles, such as Chinese, Japanese, Persian, Indian and Egyptian styles. Multicolor, primary colors, and contrast are all strongly expressed. $97 \%$ of designs contained multiple colors, with at least two colors and maximum of six colors. The most frequently used colors are red, green, and blue, which means that only $9 \%$ of the designs do not contain the three colors, showing a high preference for theses three colors. In addition, color combinations of red and green, red and blue, or all three colors are used to show high contrast and utilize complementary colors, or near complementary colors, for coloration. This study is meaningful in that it analyzes the color characteristics of Cartier's exotic designs and translates them into practical data for establishing the color strategies of companies in the global market.
\end{abstract}

Keywords: Cartier(까르띠에), Cartier color(까르띠에 색상), exotic color(이국적 색상), exotic design(이국적 디자인)

\section{Introduction}

1. The purpose of study

「까르띠에(Cartier)」는 전 세계 62개국에 278개의 매장(Richemont, 2017)을 운영 하고 있는 글로벌 럭셔리 브랜드이다. 인터브랜드(Interbrand)는 매년 100 개의 베스 
트 글로벌 브랜드를 발표하는데, 2016년 보고서에서는 62 위를 하였다. 이 보고서에서 주얼리 브랜드는 「까 르띠에」와「티파니(Tiffany\& Co.)」만 순위 안에 포함 되어 있으며, 티파니는 74위이다(Interbrand, 2016).

이렇게 강한 브랜드 가치를 지닐 수 있게 된 요인 은 다양한데, 본 논문에서는 20 세기 초「까르띠에」의 이국적 디자인과 색상 특성에 주목하였다. 자사의 특 징적인 디자인을 갖지 못했던「까르띠에」가 20세기 초 이국적 디자인을 적극적으로 발전시키면서 당대 의 스타일을 선도하고, 국제적 경쟁력을 갖추게 되었 기 때문이다. 이로 인해 20 세기 초의 이국적 디자인 은「까르띠에」의 디자인 원형으로 인정받고 있다.

1980년대에「까르띠에」가 21세기를 향한 새로운 비전을 세우고, 현대화를 위한 작업으로 '뉴 주얼리 (New Jewelry)'를 발표할 때 부활시킨 것은 바로 20 세기 초에 발표한 자사의 이국적 디자인이었다. 1982 년에 '까르띠에의 예술(L'Art de Cartier)'이라는 주제 로 이 시기를 조명했으며, 1991년까지 20세기 초에 사 용되었던 이국적 디자인의 테마들을 부활시켰다(Hong, 2015). 1930년대와 1940년대에「까르띠에」의 디자인 미학을 이끌었던 잔느 투생(Jeanne Toussaint)도 20세 기 초의 이국적 디자인을 자사의 근원적 영감으로 보 았다. 그녀는 1934년에 근원적 영감으로 회귀할 것을 주장했는데, 이는 곧 1906년경의 아이디어로 돌아가 는 것을 의미했다(Nadelhoffer, 2007). 이 시기는 대담 한 색상과 기하학적 조형으로 이국적 디자인을 실험 하던 때로 그녀는 여기에「까르띠에」의 독창성이 있 다고 믿고, 이후 디자인의 영감으로 활용했다. 이러한 인식은 현대에도 변함이 없다.「까르띠에」의 이미지 와 스타일, 헤리티지(heritage)를 총괄하고 있는 피에 르 레네로(Pierre Rainero) 역시 자사의 고유한 가치 를 20세기 초에 형성된 이국적 디자인에서 찾았다. 그는 자사의 고유한 가치인 대담하면서도 보편적인 디자인은 20세기 초 다양한 이국 문화를 이해하고 포 용하여 형성된 것이며, 오늘날의「까르띠에」또한 같 은 방식으로 추구하고 있다(Brandt, 2011)고 말했다.

이와 같이 20 세기 초에 발표한 이국적 디자인은 현재까지도「까르띠에」의 영감의 원천으로 작용하며, 글로벌 시대에 더욱 중요하게 활용되고 있다. 「까르 띠에」의 디자인에 대한 연구 중 본 논문의 주제와 근 접한 논문으로 ‘주얼리에 표현된 오리엔탈리즘: 까르
띠에를 중심으로'(Lee, 2006)가 있는데, 중국풍에 대 한 디자인 분석만 진행해「까르띠에」의 다양한 이국 적 디자인과 색상 특성을 거시적으로 고찰하는 데에 는 한계가 있다. 따라서 본 연구는 다음과 같은 목적 으로 진행하고자 한다. 첫째, 20 세기 초「까르띠에」의 이국적 디자인의 유형과 사례를 고찰한다. 둘째, 이국 적 디자인의 색상을 분석하고 특성을 도출한다. 이는 이국문화에 대한「까르띠에」의 색상 전략을 이해할 수 있는 연구로 의의를 지니며, 글로벌 시장에 진출 하고자 하는 기업들에게 실무적 응용자료로 활용하 는데 기여할 수 있을 것이다.

\section{The research method}

본 연구에서 사용하는 이국적 디자인이라는 개념 은 이국 문화에서 영감을 받아 유럽인의 시각으로 재 해석한 디자인을 말한다. 「까르띠에」는 중국과 일본, 페르시아와 인도, 이집트 문화에서 영감을 받아 자사 의 디자인 미학과 기술력을 융합해 기존과 다른 새로 운 디자인을 발표했다. 따라서 분석대상은 중국과 일 본, 페르시아와 인도, 이집트 스타일을 반영한 20세기 초「까르띠에」의 이국적 디자인이다.

연구 방법은 먼저「까르띠에」및 이국적 디자인, 이 국풍, 오리엔탈 디자인, 오리엔탈리즘을 주제로 연구 한 해외 단행본과 국내외 관련 논문, 신문 및 잡지에 대한 문헌 연구를 실시하였다. 다음으로「까르띠에」 의 전시 도록과 해외 단행본에서 20세기 초에 발표한 이국적 디자인 유형과 사례를 추출하였다.「까르띠 에」는 세계의 대표적인 공공기관에서 자사 제품들을 전시해왔기 때문에 공식 도록은 실물을 직접 분석하 지 못하는 한계를 상쇄시킬 수 있는 자료로 볼 수 있 다. 뉴욕, 모스크바, 서울, 리스본에서 개최된 「까르띠 에」전시회 도록(Calouste Gulbenkian Foundation, 2007; Moscow Kremlin Museums, 2007; National Museum of Contemporary Art, 2008; Rudoe, 1997)과 제네바 에서 개최된 「까르띠에」 단독 경매 도록(Antiquorum \& Etude Tajan, 1996), 해외 단행본(Nadelhoffer, 2007) 에서 총 248 점의 이국적 디자인을 추출했다. 248 점 중 중국과 일본 스타일이 109점, 페르시아와 인도 스타 일이 99점, 이집트 스타일이 40점이다.

이후 각 스타일별로 Natural Color System(NCS)을 적용해 색상 분석을 실시하였다. $\mathrm{NCS}$ 를 적용한 이유 
는 이 표색계의 6가지 기본 색상인 적색, 황색, 녹색, 청색, 백색, 흑색이 20세기 초「까르띠에」의 이국적 디자인에서 높은 빈도로 나타나기 때문에, 압축되고 유의미한 분석 결과를 도출할 수 있기 때문이다. 수 집한 248점을 $\mathrm{NCS}$ 의 6가지 기본 색상에 의거해 분석 하였으며, 6가지 기본 색상에 속하지 않을 경우 기타 로 분류하였다. 천연 보석은 자연적 특성상 같은 종 류라도 동일한 색상을 지니기 어렵다. 루비의 경우, 적색, 자주색, 주황색감의 적색, 분홍색감의 적색 등 다양한 색상으로 나타난다. 본 연구에서는 대표성을 위해 루비의 경우 $\mathrm{NCS}$ 의 6가지 기본 색상을 기준으 로 적색으로 분류하였으며, 적색의 근접색상까지 포 함했다는 것을 나타내기 위해 '적색계’로 명시하였다. 다른 보석들의 색상도 동일한 기준을 적용하였으며, 무색투명한 다이아몬드는 백색으로 분류하였다.

색상 분석 후 단색과 다색 수, 다색일 경우 배색 수, 높은 빈도로 사용된 색상 및 배색 상황을 검토하 였으며, 그 결과에 근거해 20 세기 초「까르띠에」의 이국적 디자인의 특성을 도출하였다. 객관성을 위해 본 연구자 외 미술사와 의류학 연구자 2 명의 검증을 거쳤으며, 이를 토대로 20 세기 초「까르띠에」의 이국 적 디자인의 색상 특성을 도출하였다.

\section{Background}

1. Colors of exotic design in the early 20th century 20세기 초 교통수단의 발전과 식민지 지배로 문화 교류가 급증하고, 산업화가 가속화되면서 이국문화에 대한 관심이 고조되었고, 페르시아와 중국, 일본, 이집
트, 아프리카 등에서 영감을 받은 디자인이 대두되었 다. 이국적 디자인은 야수주의에서 보여주는 원색을 많이 반영하였다. 〈Fig. 1〉은 야수주의를 대표하는 마 티스(Henri Matisse)의 회화로 원색을 사용해 표현적 색채미를 구현하고 있다. 이국적 디자인이 활성화되 는 촉매가 된 것은 1910년 파리에서 열린 러시아 발 레단의 〈세헤라자데〉 공연이었다. 〈Fig. 2〉에서처럼 녹색과 청색, 주황색으로 표현한 무대 장식은 문화예 술계 인사들에게 큰 영감을 주어 다양한 시도가 이어 졌다. 대표적인 사례로 패션 디자이너 폴 푸아레(Paul Poiret)는 이 공연에서 영감을 받아 하렘 팬츠, 중국풍 코트와 같은 이국적 디자인을 발표하였다(Yang \& Roh, 2013). 〈Fig. 3〉은 푸아레가 1911년에 발표한 페 르시아풍의 디자인으로 녹색과 적색, 청색, 황금색을 배 색하였다. 실내장식 분야의 대표 인물인 장 뒤낭(Jean Dunand)은 원색과 흑색, 백색을 과감하게 배색한 〈Fig. 4〉를 비롯해 래커를 사용해 강렬한 색상의 오브 제들을 발표하였다. 이와 같이 20세기 초 이국적 디 자인은 대담한 색상을 주로 사용하면서 전개되었다.

\section{Development of design in Cartier from 1847 to} early 20th century

1847 년 개점 후 약 50 년 동안「까르띠에」는 자사 의 특징을 보여주는 디자인을 확립하지 못했다. 당대 유행하던 양식들을 반영하는 정도에 머물렀으며, 주 얼리와 시계 외에 부채, 조각상, 도자기 등 다양한 품 목의 제품들을 판매했다. 「까르띠에」가 보석제품을 생산하기 시작한 것은 1850 1855년으로 추정된다 (Nadelhoffer, 2007).〈Fig. 5〉는 1850년경에 제작한 팔

$<$ Table 1> Colors of exotic design in the early 20th century

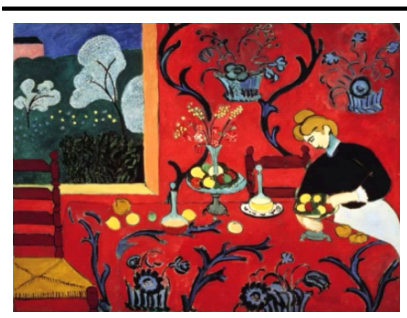

<Fig. 1> Red room, 1908. From. The State Hermitage Museum. (n.d.) https://www.hermitagemuseum.org

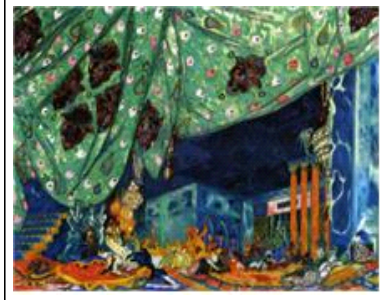

<Fig. 2> Stage design for Schérérazade, 1911.

From. Benton, Benton, \& Wood. (2003). p. 109.

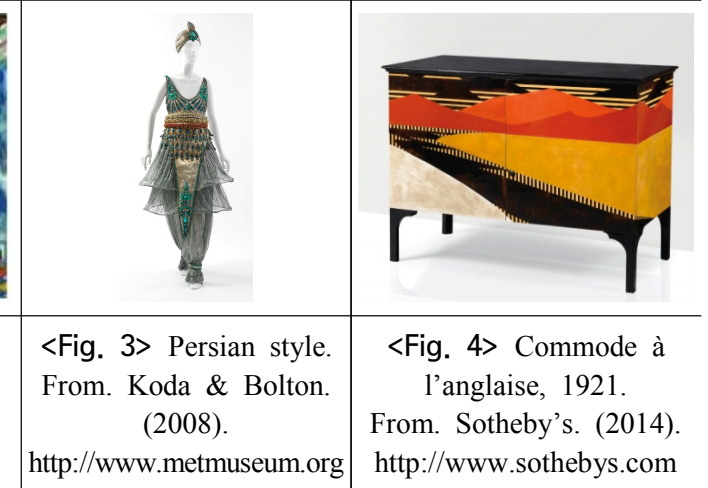


$<$ Table 2> Development of design in Cartier from 1847 to early 20th century

\begin{tabular}{|c|c|c|c|}
\hline 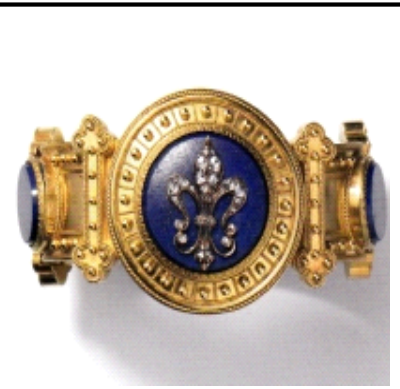 & -8 & 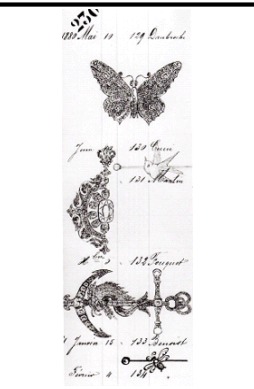 & 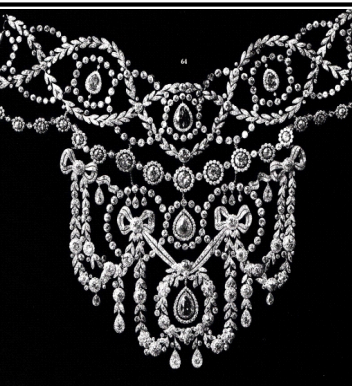 \\
\hline $\begin{array}{c}\text { <Fig. 5> Bracelet, circa } 1850 . \\
\text { From. National Museum of } \\
\text { Contemporary Art. (2008). } \\
\text { p. } 44 .\end{array}$ & $\begin{array}{c}\text { <Fig. 6> Cameo brooch, } \\
\text { circa } 1860 . \\
\text { From. National Museum } \\
\text { of Contemporary Art. } \\
\text { (2008). p. } 45 .\end{array}$ & $\begin{array}{l}<\text { Fig. } 7>\text { Sketches } \\
\text { from the stock } \\
\text { register, } 1880 . \\
\text { From. Nadelhoffer. } \\
\quad(2007) \text {. p. } 18 .\end{array}$ & $\begin{array}{l}\text { <Fig. 8> 'Garland Style' } \\
\text { necklace, } 1904 . \\
\text { From. Nadelhoffer. (2007). } \\
\text { p. } 53 .\end{array}$ \\
\hline
\end{tabular}

찌로 당시 고고학적 발굴로 유행한 복고풍을 반영해 고대의 세공기법을 적용한 것이다. 중앙의 원형 금판 과 가장자리는 가는 금실을 꼬아 만든 필리그리 (Filigree, 細線細工) 기법을 사용했으며, 그래뉼레이 션(Granulation, 鏤金細工) 기법으로 금 알갱이들을 붙 였다. 1860 년 경 제작한 〈Fig. 6〉의 브로치도 고대 신 상을 조각한 카메오를 사용해 복고풍을 반영했다. 1870 년대에 이르면 자연주의 기조와 영국의 영향으 로 자연을 모티프로 한 디자인이 유행했다. 〈Fig. 7〉 은「까르띠에」의 1880 년 재고 장부로 나비와 벌새, 돌고래, 벌을 모티프로 스케치해 유행을 반영하였다.

$\ulcorner$ 까르띠에」가 디자인 특성을 확립하기 시작한 것은 1899년 이후이다. 18세기 양식에 기초한 ‘화환 스타일 (Garland Style)'을 경쟁사보다 뛰어난 세공 기법과 고 품질의 플래티늄을 사용해 유럽은 물론 미국의 신흥부 자들에게도 인기가 확산되었다. 화환, 꽃줄 장식(swag), 태슬(tassel), 레이스, 리본 매듭을 모티프로 하여 백색 재료인 다이아몬드와 플래티늄, 진주로 제작해 우아함 을 높이고, 당시 유행한 파스텔 색조의 패션과도 잘 어 울린 '화환 스타일'은 상류층의 높은 지지를 받아(Hong, 2006)「까르띠에」의 우위를 다지는 발판이 되었다. 〈Fig. $8>$ 은 1904년에 제작한 전형적인 ‘화환 스타일'의 목걸 이로 18 세기의 화려한 주얼리 문화를 재현하고 있다.

러시아 발레단의 파리 공연을 계기로「까르띠에」 는 이국적 디자인으로 빠르게 선회했다. 오랫동안 수 집한 다양한 문화권의 자료와 유물을 토대로 역사적 고증에 기반을 두고 유물을 직접 제품에 접목한 차별
화된 이국적 디자인을 발표하면서 디자인 미학을 확 립하고, 경쟁사들보다 우위를 점하게 되었다. 또한 1902년에 런던, 1909년에 뉴욕 지점을 개설하고, 인 도와 보석 무역을 하여 국제적 네트워킹을 확대해 이 국적 디자인의 수용과 확산에 박차를 가했다. 그 결 과, 1939 년까지 유럽의 주요 왕실과 이집트, 태국에 이르기까지 15 개 왕실의 공식공급자로 채택되어 국 제적 명성을 구축하였다(Nadelhoffer, 2007).

\section{Natural Color System(NCS)}

Natural Color System(NCS)는 1972년 스웨덴 색채 연구소에서 개발한 세계적인 색채표기 시스템이다. 독 일의 생리학자인 헤링(Karl Ewald Konstantin Hering) 의 반대색설(Opponent Color Theory)을 근거로 하고 있다. 헤링은 1878 년경 색과 색지각에 관해 연구하였 고, 지각작용의 진상을 밝혀내었다. 그는 적색, 황색, 녹색, 청색을 시각적인 기본이라고 보고, 기존의 3 색 이론에 동의하지 않았다. NCS의 특징은 뉘앙스(nuance) 를 기준으로 색의 관계성을 부여한 친 인간적 색채체 계이다. 그리고 인간의 시각기관을 통해 색을 지각하 는 원리로 색의 속성을 명도, 색도, 색상의 3속성으로 구분하지 않고, 색상과 색조의 개념인 뉘앙스로 구분 하고 있다. 이는 색조 중심의 배색을 할 때 용이한 구 조적 특징을 지닌다. 또한 거리, 빛, 표면 구조와 같은 색채지각변수에 따른 관찰자의 반응을 통계적으로 적 용하여 인간과 색채, 환경과의 연계성을 높인 색체계 이다(Park, 2005). NCS의 기본색상은 〈Fig. 9〉와 같이 


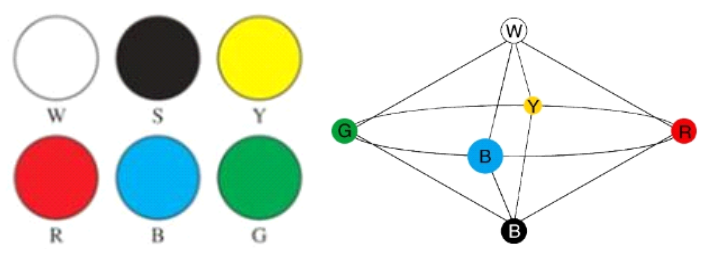

<Fig. 9> NCS elementary colors

적색, 황색, 녹색, 청색, 백색, 흑색으로 이루어져 있다.

\section{Styles and Cases of Exotic Design of Cartier}

20세기 초「까르띠에」는 다양한 이국 문화에서 영 감 받은 디자인들을 적극적으로 발표하기 시작했다. 이 시기 이국적 디자인의 유형을 분류하기 위해 다음 과 같은 기준을 적용하였다. 첫째, 「까르띠에」의 전시 회 도록에서 이국적 디자인으로 범주화되어 있으며, 둘째, 디자인 유형으로 분류할 정도의 유의미한 제품 수가 있는지를 고려하였다. 그 결과, 영향을 받은 문 화권으로 기준을 중국과 일본 스타일, 페르시아와 인 도 스타일, 이집트 스타일로 분류하였으며 각각의 대 표적 사례는 아래와 같다.

\section{Chinese and Japanese style}

중국과 일본은 유럽의 문화예술에 폭넓은 영향을 미쳐 왔다. 중국풍은 17 세기 후반부터, 일본풍은 19세 기 중후반부터 유행해 프랑스어로 중국풍은 시누와 즈리(Chinoiserie), 일본풍은 자포니즘(Japonism)이라 고 불렸다(Hong, 2008).「까르띠에」는 1919년에 중국 의 음양(陰陽)사상에 근거해 〈Fig. 10〉과 같은 펜던트 를 발표했다. 음은 검정색 오닉스로, 양은 다이아몬드 로 표현했으며, 금속 체인 대신에 실크 코드(silk cord) 를 사용해 동양적 느낌을 더했다. 1926년에는 〈Fig. $11>$ 처럼 비취로 귀걸이를 제작했다. 중앙에는 장수를 뜻하는 한자 수(壽)를 적색 에나멜로 표현해 비취의 녹 색과 강렬한 대비를 주었다. 일본풍으로는 〈Fig. 12〉 가 있다. 일본 신사(神社) 입구에 세우는 도리이(鳥居) 를 모티프로 하여 1923년에 제작한 탁상용 시계이다. 무색의 투명한 백수정과 오닉스, 에나멜을 사용해 흑 백 대비를 주었고, 상단에는 복덕을 가져오는 신인 호테에(布袋)로 장식했다.

\section{Persian and Indian style}

러시아 발레단의 파리 공연을 계기로「까르띠에」 는 페르시아풍 디자인을 확대해 나갔다. 〈Fig. 13〉은 1912년에 제작한 브로치이다. 하단의 직사각형에는 이슬람 문화권에서 볼 수 있는 상징인 '행운의 눈(lucky eye)'을 나타내고 있다. 〈Fig. 14〉는 1924년에 제작한 화장품 케이스로 이슬람 문양에 터키석과 비취, 자개, 진주로 화려하게 장식했다. 이슬람과 힌두 문화가 혼 합된 무굴양식의 디자인도 발표하였다. 페르시아와 무 굴 예술에서 자주 볼 수 있는 보테(boteh) 문양을 활 용해(Krishnan \& Kumar, 2007), 1925년에〈Fig. 15〉 와 같은 장식 핀을 제작했다. 녹색 비취와 적색 루비, 검 정색 에나멜을 사용해 강렬한 색상 대비를 주고 있다.

\section{Egyptian style}

이집트에 대한 유럽인의 관심은 나폴레옹의 이집 트 원정과 수에즈 운하 건설로 인해 19세기에도 존재 했다. 20 세기 초에 이집트풍이 큰 유행을 하게 된 것 은 1922년에 투탕카멘 무덤이 발견되면서였다. 파라 오의 황금 마스크와 왕관, 가슴 장식 등 많은 유물이 발굴되면서 문화예술계는 물론 대중들까지 관심을 갖게 되었다.「까르띠에」는 1924년에〈Fig. 16〉과 같 은 광고를 하였다. '투탕카멘이 모던 주얼리에 영향 을 미치다'라는 제목으로 다양한 디자인의 이집트풍 주얼리를 실었다. 또한 같은 해에〈Fig. 17〉과 같이 생명과 부활을 상징하는 스캐럽(scarab)을 모티프로 브로치를 선보였다. 청색과 백색으로 명시성을 높이 고, 흑색 에나멜과 녹색 에메랄드로 엑센트를 주었다. 청색 날개는 기원전 10 세기 후반에 만든 파이앙스 (faience)를 사용했다. 1934년에는 연꽃을 모티프로 활 용해〈Fig. 18〉과 같은 티아라를 제작했다. 양식화한 연꽃들을 다이아몬드로 섬세하게 세팅하였으며, 정수 리에서 아래로 갈수록 점점 작아지게 디자인했다.

\section{Cases applied to present day}

위에서 살펴본 이국적 디자인은 현대에도「까르띠 에」의 디자인 모티프로 활용되면서 진화하고 있다. 「까르띠에」의 공식 홈페이지에는 〈Fig. 19〉처럼 인도 에서 영감을 받아 최근에 제작한 하이 주얼리가 소개 되어 있다. '인도의 영감(Indian Influences)'이라는 동 영상도 탑재하여 20 세기 초의 이국적 디자인을 현대 
$<$ Table 3> Styles and cases of exotic design in Cartier

\begin{tabular}{|c|c|c|c|}
\hline \multirow[t]{2}{*}{$\begin{array}{l}\text { Chinese and } \\
\text { Japanese } \\
\text { style }\end{array}$} & $\|$ & $\begin{array}{l}6 \\
8 \\
8 \\
8 \\
63\end{array}$ & $\overrightarrow{0}$ \\
\hline & $\begin{array}{c}<\text { Fig. 10> 'Yin-Yang' pendant, } \\
1919 . \\
\text { From. Nadelhoffer. (2007). } \\
\text { p. } 188 .\end{array}$ & $\begin{array}{c}\text { <Fig. 11> Jade earrings, } 1926 . \\
\text { From. Rudoe. (1997) } \\
\text { p. } 195 .\end{array}$ & $\begin{array}{l}<\text { Fig. 12> Portique mystery } \\
\text { Clock, } 1923 \text {. } \\
\text { From. Antiquorum \& Etude } \\
\text { Tajan. (1996). p. } 310 .\end{array}$ \\
\hline \multirow[t]{2}{*}{$\begin{array}{l}\text { Persian and } \\
\text { Indian } \\
\text { style }\end{array}$} & 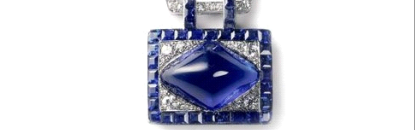 & 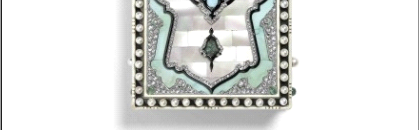 & \\
\hline & $\begin{array}{c}\text { <Fig. 13> Brooch-pendant, } 1912 . \\
\text { From. National Museum of } \\
\text { Contemporary Art. (2008). } \\
\text { p. } 105 .\end{array}$ & $\begin{array}{c}\text { <Fig. 14> Vanity case, } 1924 . \\
\text { From. Nadelhoffer. (2007). } \\
\text { p. } 203 .\end{array}$ & $\begin{array}{c}\text { <Fig. 15> Boteh cliquet pin, } 1925 . \\
\text { From. National Museum of } \\
\text { Contemporary Art. (2008). } \\
\text { p. } 158 .\end{array}$ \\
\hline \multirow[t]{2}{*}{$\begin{array}{c}\text { Egyptian } \\
\text { style }\end{array}$} & & & as \\
\hline & $\begin{array}{l}\qquad \text { <Fig. 16> } \\
\text { Advertisement, The Illustrated } \\
\text { London News, 1924. } \\
\text { From. Rudoe. (1997). p. } 136 .\end{array}$ & $\begin{array}{c}<\text { Fig. 17> Scarab brooch, } 1924 . \\
\text { From. Nadelhoffer. (2007). } \\
\text { p. } 145 .\end{array}$ & $\begin{array}{c}\text { <Fig. 18> 'Halo' tiara, } 1934 . \\
\text { From. Rudoe. (1997). } \\
\text { p. } 145 .\end{array}$ \\
\hline \multirow[t]{2}{*}{ Contemporary } & & & \\
\hline & $\begin{array}{l}\text { <Fig. 19> Tutti-Frutti } \mathrm{n} \\
\text { From. Cartier. (n.d } \\
\text { http://www.cartier.ce }\end{array}$ & $\begin{array}{l}\text { ecklace. } \\
\text { om }\end{array}$ & $\begin{array}{l}\text { 20> Panda wristwatch. } \\
\text { WorldTempus. (n.d.). } \\
\text { //en.worldtempus.com }\end{array}$ \\
\hline
\end{tabular}


에도 응용하고 있다. 이전 디자인들을 검토해 보면 중국의 판다를 모티프로 한 〈Fig. 20〉처럼 20세기 초 발표했던 다른 이국문화도 지속적으로 활용해왔음을 볼 수 있다.

\section{Color Characteristics of Exotic Design of Cartier}

20세기 초「까르띠에」의 이국적 디자인 248점을 Natural Color Stytem(NCS)에 의거해 양적 분석한 결 과는 다음과 같다. 중국과 일본 스타일에서는 $99 \%$ 가 다색으로 가장 높은 빈도로 사용된 색상은 적색계, 녹 색계, 청색계 순이며, $93 \%$ 사용되었다. 페르시아와 인 도 스타일에서는 $95 \%$ 가 다색으로 가장 높은 빈도로 사용된 색상은 녹색계, 적색계, 청색계 순이며, $92 \%$ 사용되었다. 이집트 스타일에서는 $98 \%$ 가 다색으로 가 장 높은 빈도로 사용된 색상은 청색계, 녹색계, 적색 계 순이며, $89 \%$ 사용되었다. 또한 모든 스타일에서 이 세 가지 색상을 위주로 2 색 또는 3 색 배색을 하여 보 색과 근접보색에 의한 대비가 특징적으로 나타났다. 이러한 결과를 고려할 때 20세기 초「까르띠에」의 이 국적 디자인의 색상 특성으로 다색성과 원색성, 대비 성을 도출하였으며, 각각의 분석 결과는 다음과 같다.

\section{Multicolor}

총 248 점의 분석 대상 중 $97 \%$ 가 다색이며, 단색은 $3 \%$ 에 불과했다. 단색은 모두 백색계로 다이아몬드가 사용되었다. 「까르띠에」가 이국적 디자인을 본격적으 로 전개하기 이전의 디자인인 '화환 스타일'은 백색 계를 사용한 단색 기조가 우세하였다. 그러나 이국적 디자인에서는 최소 2 색에서 최대 6 색 배색을 사용하 여 다색성이 두드러졌다. 〈Fig. 21〉처럼 4색 배색이 $43 \%$ 로 가장 많으며, 3 색 $30 \%, 2$ 색 $14 \%, 5$ 색 $11 \%, 6$ 색 $2 \%$ 순으로 4 색과 3 색 배색이 $73 \%$ 에 달한다.

\section{Primary color}

가장 높은 빈도로 사용된 색상은 적색계와 녹색계, 청색계로 강한 원색성을 지니고 있다. 이 세 가지 색 이 들어가지 않은 제품은 $9 \%$ 에 불과하다. 각 스타일 별로 많이 사용된 색상이 다른 점도 주목할 점이다. 〈Fig. 22〉처럼 중국과 일본 스타일은 적색계(52\%) -

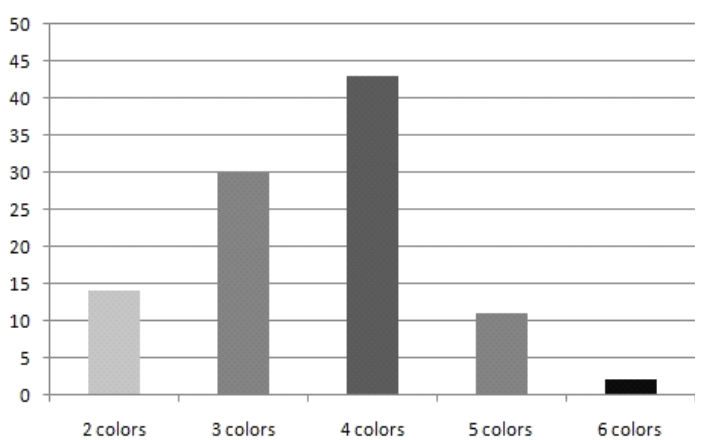

$<$ Fig. 21> The number of coloration

녹색계 $(30 \%)$ - 청색계 $(18 \%)$, 페르시아와 인도 스타일 은 녹색계 $(45 \%)$ - 적색계 $(32 \%)$ - 청색계 $(23 \%)$, 이집 트 스타일은 청색계(46\%) - 녹색계 $(36 \%)$ - 적색계 $(18 \%)$ 순으로 나타났다. 중국과 일본 스타일은 적색 계, 페르시아와 인도 스타일은 녹색계, 이집트 스타일 은 청색계가 $50 \%$ 전후로 나타나, 각 문화권에 대한 「까르띠에」의 색상 전략을 알 수 있다.

적색계로는 루비, 산호, 에나멜, 녹색계로는 에메랄 드, 비취, 청색계로는 사파이어, 라피스 라줄리가 주 로 사용되었다. 유럽 문화권에서 전통적으로 사용된 루비와 사파이어, 에메랄드 외에 중국과 일본 스타일 에서는 산호와 에나멜, 비취로 적색계와 녹색계를, 이 집트 스타일에서는 라피스 라줄리로 청색계를 나타 내면서 불투명한 재료로 원색을 더욱 강조했다.

\section{Contrast}

적색과 녹색, 적색과 청색으로 2 색 배색하거나 세

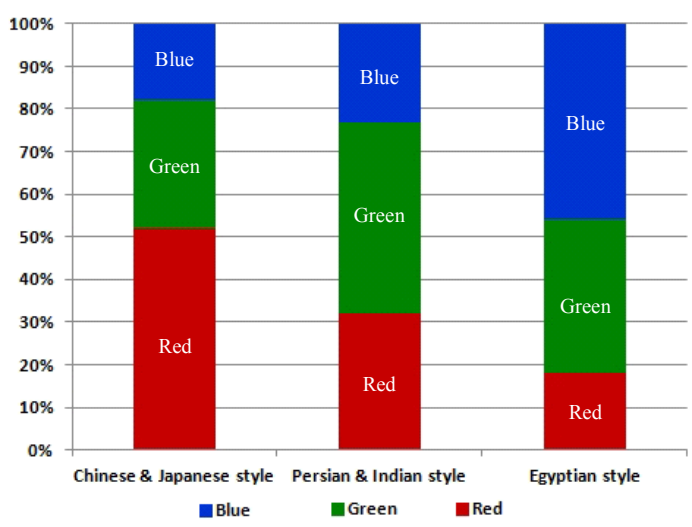

$<$ Fig. 22> The most frequently used colors 
$<$ Table 4> Examples of contrast

\begin{tabular}{|c|c|c|c|}
\hline & Chinese \& Japanese style & Persian \& Indian style & Egyptian style \\
\hline $\begin{array}{l}\text { Primary } \\
\text { coloration }\end{array}$ & Green & Green & Blue \\
\hline \multirow[t]{2}{*}{ Cartier } & & & \\
\hline & $\begin{array}{c}\text { <Fig. 23> Pendant watch, } 1929 . \\
\text { From. National Museum of } \\
\text { Contemporary Art. (2008). } \\
\text { p. } 172 .\end{array}$ & $\begin{array}{c}\text { <Fig. 24> Tutti-Frutti necklace, } \\
1933 . \\
\text { From. National Museum of } \\
\text { Contemporary Art. (2008). p. } 164 .\end{array}$ & $\begin{array}{c}\text { <Fig. 25> Cigarette case, } \\
1929 . \\
\text { From. Nadelhoffer. (2007). } \\
\text { p. } 148 .\end{array}$ \\
\hline \multirow[t]{2}{*}{ Relic } & & & ) \\
\hline & $\begin{array}{l}\text { <Fig. 26> Snuff bottle, } \\
\text { 1780-1900. } \\
\text { From. Christie's. (2012). } \\
\text { http://www.christies.com }\end{array}$ & $\begin{array}{l}<\text { Fig. 27> Turban ornament, early } \\
\text { 19th century. } \\
\text { From. Krishnan \& Kumar. (2007). } \\
\text { p. } 242 .\end{array}$ & $\begin{array}{c}\text { <Fig. 28> Tutankhamun } \\
\text { gold mask. } \\
\text { From. Verweij. (n.d.). } \\
\text { https://www.pinterest.co.kr }\end{array}$ \\
\hline
\end{tabular}

가지 색 모두를 3 색 배색하여 보색 또는 근접보색에 의한 높은 대비성을 나타내고 있다. 여기에 백색과 흑색을 배색해 분리효과를 줘 명시성을 높이기도 하 였다. 중국과 일본 스타일은 적색계와 녹색계 배색이 $38 \%$, 페르시아와 인도 스타일은 적색계, 녹색계, 청 색계 배색이 $31 \%$, 이집트 스타일은 적색계와 청색계 배색이 $28 \%$ 로 가장 높게 나타났다. 이러한 배색을 기 본으로 황금과 터키석을 사용하여 액센트 효과와 이 국적 느낌을 부가하였다. 황금은 중국, 터키석은 이집 트, 페르시아와 인도 스타일에서 사용이 두드러졌다. 이러한 대비적 배색의 대표 사례로〈Fig. 23〉 〈Fig. 25)가 있다.

각 문화권의 전통 배색을 고려할 때「까르띠에」의 이러한 접근은 해당 국가의 문화예술에 대한 이해를 바탕으로 한 것으로 보인다. 유물을 확인해 보면 〈Fig. 26〉은 1780 1900년에 중국에서 제작한 비연호 (鼻煙壼, snuff bottle)로 산호와 비취로 적색과 녹색 대비를 보여준다. 〈Fig. 27〉은 19세기 초 인도에서 제 작한 터번 장식이다. 에나멜 공예로 유명한 자이푸르
(Jaipur)에서 제작한 것으로 녹색과 청색, 적색의 대비 가 이 곳 에나멜의 특징이다. 〈Fig. 28〉은 투탕카멘의 황금마스크로 적색과 청색 대비를 보여준다.

\section{Conclusion}

국경을 넘어선 치열한 경쟁 구도가 심화되면서 이 국문화에 대한 이해와 효과적인 전략 수립의 필요성 이 증대되고 있다. 럭셔리 주얼리 브랜드로 세계적인 명성을 구축한「까르띠에」는 110 여 년 전에 다양한 문화를 재해석해 이국적 디자인을 적극적으로 모색 하고 발전시켰다. 그 결과, 국제적인 경쟁력을 확보하 였으며, 현재까지도「까르띠에」의 디자인 원형으로 활용하고 있다.

본 연구에서는「까르띠에」의 디자인 역사에서 중 요한 전환점이 된 20세기 초의 이국적 디자인의 유형 과 색상 특성에 대해 분석하였으며, 다음과 같다. 1847 년에 개점한「까르띠에」는 50 여 년 간 자사의 특 징적인 디자인을 개발하지 못하고, 당대 유행하던 양 
식들을 반영하는 수준에 머물렀다. 1899년 이후부터 독자적인 디자인 개발과 제작에 주력하기 시작했으며, 18세기 양식을 응용한 ‘화환 스타일'로 두각을 나타 내었다. 교통수단의 발전과 식민지 지배로 문화 교류 가 급증하고 산업화가 가속화되면서 이국문화에 대 한 관심이 고조되었고, 이국적 디자인이 대두되었다. $\ulcorner$ 까르띠에」또한 다양한 이국적 디자인을 발표하였 다.「까르띠에」가 주력한 이국적 디자인의 유형은 중 국과 일본, 페르시아와 인도, 이집트 스타일로 나눌 수 있다.

색상 특성은 다색성과 원색성, 대비성을 강하게 나 타내고 있다. 총 248점의 분석 대상 중 $97 \%$ 가 다색으 로 최소 2 색에서 최대 6 색 배색을 사용하였다. 4색 배색이 $43 \%$ 로 가장 많으며, 3 색 $30 \%, 2$ 색 $14 \%, 5$ 색 $11 \%, 6$ 색 $2 \%$ 순으로 4 색과 3 색 배색이 $73 \%$ 에 달한 다. 가장 높은 빈도로 사용된 색상은 적색계와 녹색 계, 청색계로 이 3 색이 들어가지 않은 비율은 $9 \%$ 에 불과해 높은 원색성을 보여주고 있다. 중국과 일본 스타일은 적색계 $(52 \%)$ - 녹색계 $(30 \%)$ - 청색계 $(18 \%)$, 페르시아와 인도 스타일은 녹색계 $(45 \%)$ - 적색계 $(32 \%)$ - 청색계 $(23 \%)$, 이집트 스타일은 청색계 $(46 \%)$ - 녹색계 $(36 \%)$ - 적색계 $(18 \%)$ 순으로 나타났다. 또한 적색과 녹색, 적색과 청색으로 2 색 배색하거나, 세 가 지 색 모두를 3 색 배색하여 보색 또는 근접보색에 의 한 높은 대비성을 나타내고 있다. 여기에 백색과 흑 색을 배색해 분리효과를 줘 명시성을 높이기도 하였 다. 중국과 일본 스타일은 적색계와 녹색계 배색이 $38 \%$, 페르시아와 인도 스타일은 녹색계, 적색계, 청 색계 배색이 $31 \%$, 이집트 스타일은 청색계와 적색계 배색이 $28 \%$ 로 가장 높게 나타났다.

이상의 연구 결과를 통해 20세기 초에 문화예술계 에서 유행했던 대담한 색상이「까르띠에」의 이국적 디자인에서도 적극적으로 활용되었음을 알 수 있다. 「까르띠에」는 이전의 '화환 스타일'에서 보여준 백색 계의 색상에서 탈피하여 적색, 녹색, 청색을 핵심 색 상으로 사용해 강한 다색성과 원색성, 대비성으로 이 국적 색상미를 구현하였다. 또한 중국과 일본 스타일 은 적색계를, 페르시아와 인도는 녹색계를, 이집트 스 타일은 청색계를 $50 \%$ 전후로 가장 많이 사용해 각 문화권에 대한「까르띠에」의 색상 전략을 알 수 있다. 그리고 이러한 특성은 서론에서 피에르 레네로가 언
급한 바와 같이 현대에도「까르띠에」의 고유한 가치 인 대담하면서도 보편적인 디자인의 원형으로 계승 되고 있다.

이러한「까르띠에」의 색상 전략이 디자인과 세련 되게 결합하여 국적을 초월한 성과를 창출하였고, 현 대에도 지속적으로 활용되고 있는 점을 고려할 때, 본 연구는 글로벌 시장 진출과 경쟁력 강화를 제고하는 기업들에게도 실무적으로 기여할 수 있을 것으로 본 다. 본 연구에서 고찰한 문화권을 대상으로 하는 경 우는 물론 한국의 전통문화를 응용한 디자인 및 마케 팅, 브랜딩에서의 색상 전략 수립에 응용자료로 활용 할 수 있다는 의의가 있다.

\section{References}

Antiquorum \& Etude Tajan. (1996). The magical art of Cartier. Geneva: Antiquorum Editions.

Benton, C., Benton, T., \& Wood, G. (2003). Art Deco 1910-1938. London: V \& A Publishing.

Brandt, T. (2011, February 9). Pierre Rainero, guardian angel of the Cartier style. The HH Journal, Retrieved May 5, 2017, from https:/journal.haute horlogerie.org/en/pierre-rainero-guardian-angel-ofthe-cartier-style

Calouste Gulbenkian Foundation. (2007). Cartier 1899 1949: The journey of a style. Milan: Skira.

Cartier. (n.d). Tutti-frutti necklace. Retrieved April 1, 2017, from http://www.cartier.com/en-us/collections/ jewelry/exceptional-creations/tutti-frutti-high-jewe lry/h7000161-high-jewelry-necklace.html

Christie's. (2012). A mottled green jadeite snuff bottle, Retrieved May 5, 2017, from http://www.christies. com/lotfinder/searchresults.aspx?\&searchtype $=p \&$ searchfrom=header \&lid $=1 \&$ entry $=$ chinese $\% 20$ cor al\%20jade\&action=paging $\& p g=$ all

Hong, J. Y. (2006). Antique jewelry. Seoul: Sumakse.

Hong, J.-Y. (2008). A study on Chinese styles observed in European gem-set craft in the early 20th century. The Journal of the Korea Society of Art \& Design, 11(3), 1-19.

Hong, J. Y. (2015). A study on the characteristics 
and influence of the development of foreign luxury jewelry brands in Korea. Unpublished doctoral dissertation, Ewha Womans University, Seoul, Korea.

Interbrand. (2016). Best global brands 2016 rankings. Retrieved May 5, 2017, from http://interbrand.com/ best-brands/best-global-brands/2016/ranking

Koda, H., \& Bolton, A. (2008, September). Paul Poiret (1879 1944). The Metropolitan Museum of Art, Retrieved April 1, 2017, from http://www.metmu seum.org/toah/hd/poir/hd_poir.htm

Krishnan, U. R. B., \& Kumar, M. S. (2007). Indian jewellery: Dance of the peacock. Mumbai: India Book House.

Lee, J. E. (2006). Orientalism in jewelry: Concentrated on Cartier style. Journal of Korea Design Forum, 13, 327-339.

Moscow Kremlin Museums. (2007). Cartier: Innovation through the 20th century. Paris: Flammarion.

Nadelhoffer, H. (2007). Cartier. San Francisco, CA: Chronicle Books.

National Museum of Contemporary Art. (2008). The art of Cartier. Seoul: MIC Inc.

Park, J.-E. (2005). A study on systemic program of Birren's color harmony by Natural Color System. Journal of Korean Society of Color Design Stu- dies, 1(1), 25-34.

Richemont. (2017). Annual report FY 2017. Retrieved June 3, 2017, from https://www.richemont.com/ images/investor_relations/reports/annual report/20 17/ar_fy2017_business_review_f73jdsf82s64r2.pdf

Rudoe, J. (1997). Cartier: 1900 1939. New York: Harry N. Abrams.

Sotheby's. (2014). Jean Dunand \& Jean Goulden. Retrieved April 11, 2017, from http://www.sothebys. com/en/auctions/ecatalogue/lot.13.html/2014/collection-privee-felix-marcilhac

The State Hermitage Museum. (n.d.). Red Room(Harmony in Red): Matisse, Henri. 1869-1954. Retrieved May 5, 2017, from https://www.hermitage museum.org/wps/portal/hermitage/digital-collectio n/01.+Paintings $/ 28389 /$ ?lng=en

Verweiji, A. [Amber]. (n.d.). Tutankhamun in Egypt [Pinterest]. Retrieved June 3, 2017, from https:// www.pinterest.co.kr/explore/tutankhamun

WorldTempus. (n.d.). Montre décor panda. Retrieved May 15, 2017, from http://static.worldtempus.com/ cache/product/0/1/01_13_688x688.jpg

Yang, M.-J. \& Roh, Y.-S. (2013). A study on characteristics of art deco appeared in the works of Paul Poiret. A Treatise on The Plastic Media, 16 (4), 127-136. 